\title{
Comportement alimentaire et évolution pondérale de bovins, d'ovins et de caprins exploitant un même parcours : effet de la composition floristique du pâturage, et du chargement
}

\author{
C Sall ${ }^{1}, \mathrm{~T}_{\text {Nolan }}^{2}$, J Connolly ${ }^{3}, \mathrm{MM}$ Thiam ${ }^{1}, \mathrm{M}$ Diene ${ }^{1}$ \\ ' Laboratoire national de l'Élevage et de Recherches vétérinaires, BP 2057, Dakar-Hann, Sénégal; \\ 2 Teagasc, Athenry Research and Development Centre, Athenry, Co Galway; \\ 3 Statistics Department, University College, Belfield, Dublin 4, Republique d'Irlande
}

Summary - Effect of pasture floristic composition and stocking rate on nutrition and performance of mixed grazing cattle, sheep and goats. Mixed grazing improves vegetation and animal productivity. The complexity of Sahelian grazing ecosystems complicated the definition of stocking rate.

Les espèces herbivores ont un comportement alimentaire différent et complémentaire au pâturage (Sall et al, 1988). Leur association présente de l'intérêt pour la préservation de la végétation, et le maintien ou l'augmentation des productions animales (Nolan, 1980). Cette pratique, bien qu'ancienne en zone sahélienne, se heurte à la définition du chargement et du ratio interespèces animales optimum, selon le type de végétation, pour la meilleure gestion des parcours. Avec l'expérience menée depuis l'hivernage de 1990 au CRZ de Dahra (Sénégal), nous avons voulu montrer la complexité de la définition du paramètre "chargement» en pâturage hétérogène sahélien et de la productivité globale du pâturage ( $\mathrm{kg}$ poids vif/animal/ha) avec la méthode traditionnelle de conduite des troupeaux.

Matériel et méthodes - Le site expérimental se trouve dans la région sahélienne du Sénégal (latitude $15^{\circ} 23^{\prime} \mathrm{N}$, longitude $15^{\circ} 30^{\prime} \mathrm{W}$ ) caractérisée par une longue saison sèche et une saison des pluies de juillet à octobre. La composition du tapis herbacé est déterminée par la méthode des points quadrats (Poissonnet et César, 1972). Dans la présentation des résultats, les espèces sont regroupées en 4 familles: graminées, légumineuses, convulvulacées, et autres herbacées. La biomasse est mesurée par la méthode de la récolte intégrale (Levang et
Grouzis, 1980), en octobre, décembre, février, avril et juin. Des mâles entiers de bovins zébus Gobra, d'ovins Peulh et de caprins sahéliens, sevrés, sont conduits simultanément au pâturage d'août 1990 à juin 1991 sur 3 parcelles, avec les chargements indiqués au tableau $I$. Leurs choix alimentaires sont déterminés par la méthode "Collecte du Berger" (Guérin, 1988), et une analyse bromatologique est faite sur chaque échantillon prélevé.

Résultats et discussion - Le retard des pluies et la faible pluviométrie $(216 \mathrm{~mm})$ ont limité la biomasse végétale à moins de $500 \mathrm{~kg}$ de matière sèche/ha et ont défavorisé les Légumineuses ( 1 à $3 \%$ des points quadrats). Les Graminées, qui sont présentes partout, sont en proportion plus élevée dans la parcelle $3(75 \%)$ que dans les parcelles $1(24 \%)$ et $2(52 \%)$. La parcelle 1 est caractérisée par une forte proportion de convulvulacées $(46 \%)$ et une densité élevée de plantes ligneuses de bonne appétibilité et de haute valeur nutritive (Sall et al, 1988). La sélection de Convulvulacées, qui avaient une fréquence de présence de $46 \%, 21 \%$ et $7 \%$ dans la végétation des parcelles 1,2 et 3 , est d'un bon niveau : respectivement $60 \%, 58 \%$ et $53 \%$ de la ration. Les différences entre les rations annuelles portent sur les proportions de Graminées ingérées (respectivement 
$15 \%, 21 \%$ et $26 \%$ pour les parcelles 1,2 et 3), qui reflètent leurs proportions dans la végétation ( $24 \%, 52 \%$ et $75 \%)$.

Les animaux du parcours le moins chargé (parcelle 1) ont présenté la meilleure évolution du poids à l'hectare : celui-ci est passé de $32,9 \mathrm{~kg}$ à $53,9 \mathrm{~kg}$ soit un gain de poids total de $21 \mathrm{~kg} / \mathrm{ha}$. Malgré des chargements initiaux presque identiques, les animaux des parcelles 2 et 3 ont présenté des gains de poids très différents : 20,8 et $10,8 \mathrm{~kg} / \mathrm{ha}$, respectivement (tableau II).

En conclusion, un pâturage sahélien d'une phytomasse inférieure à $500 \mathrm{~kg}$ de matière sèche/ha peut avoir, après 10 mois d'élevage, une productivité faible ou élevée selon le type de végétation exploitée. Cela remet en cause la formule de calcul de la capacité de chargement (Boudet, 1978), ne tenant compte que du poids de l'animal et de la surface pâturée. Une telle formule devra inclure d'autres paramètres, tels que le type de végétation (composition floristique et phytomasse), les animaux élevés (espèces herbivores, ratios interespèces) et le mode de conduite du troupeau (pâturage simple ou mixte, temps de séjour, distance parcourue).

Boudet G (1978) Manuel et précis d'élevage, $n^{\circ} 4$, IEMVT

Guérin H (1988) Rev Elev Méd Vét Pays Trop $14,419-426$

Levang P, Grouzis M (1980) Acta CEcol Plant 1 (3), 231-244

Nolan T (1980) Proc Workshop on mixed grazing (T Nolan, J Connolly, eds) Teagasc, Dublin, 1-19
Poissonnet P, César J (1972) Ann Univ Abidjan, série $E, 5,577-601$

Sall C, Guillon JM, Nolan T, Connolly J (1988) Publ $n^{\circ} 31$ et $n^{\circ} 41$, LNERV, BP 2057, Dakar, Sénégal

Tableau I. Superficies, espèces et nombres d'animaux, et chargements.

\begin{tabular}{lccc}
\hline & \multicolumn{3}{c}{ Parcelles } \\
& 1 & 2 & 3 \\
& & & \\
& & & \\
Superficies (ha) & 55,8 & 53,8 & 48,1 \\
Espèces (n) & & & \\
$\quad$ Bovins & 14 & 15 & 15 \\
$\quad$ Ovins & 18 & 19 & 20 \\
$\quad$ Caprins & 24 & 26 & 26 \\
Chargement (UBT*/ha) & 0,13 & 0,16 & 0,17 \\
& & & \\
\hline
\end{tabular}

- UBT : unité bovin tropical (450 kg de poids vif).

Tableau II. Composition floristique de la ration ingèrée, selon les parcelles, toutes espèces animales et mois de mesures confondus (en pourcentage des points quadrats).

\begin{tabular}{lcrr}
\hline Espèces végétales & \multicolumn{3}{c}{ Parcelles } \\
& 1 & 2 & 3 \\
\hline Graminées & 15 & 21 & 26 \\
Légumineuses & 0,5 & 1 & 4 \\
Convulvulacées & 60 & 58 & 53 \\
Autres herbacées & 14 & 13 & 15 \\
& & & \\
\hline
\end{tabular}

